\title{
The main factor influencing the tensile properties of surface nano-crystallized graded materials
}

\author{
Jianjun $\mathrm{Li}^{\mathrm{a}}$, Shaohua Chen ${ }^{\mathrm{a}, *}$, Xiaolei $\mathrm{Wu}^{\mathrm{a}}$, Aikah Soh $^{\mathrm{b}}, \mathrm{Jian} \mathrm{Lu}^{\mathrm{c}}$ \\ ${ }^{a}$ LNM, Institute of Mechanics, Chinese Academy of Sciences, Beijing 100190, China \\ b Department of Mechanical Engineering, The University of Hong Kong, Hong Kong, China \\ ${ }^{c}$ Mechanical Engineering, Hong Kong Polytechnic University, Hong Kong, China
}

\section{A R T I C L E I N F O}

\section{Article history:}

Received 8 July 2010

Received in revised form 13 July 2010

Accepted 14 July 2010

\section{Keywords:}

Surface nano-crystallized graded material

Residual stress

Work hardening

Finite element method

\begin{abstract}
A B S T R A C T
The improved mechanical properties of surface nano-crystallized graded materials produced by surface severe plastic deformation ( $\mathrm{S}^{2} \mathrm{PD}$ ) are generally owing to the effects of the refined structure, workhardened region and compressive residual stress. However, during the $S^{2} P D$ process, residual stress is produced simultaneously with work-hardened region, the individual contribution of these two factors to the improved mechanical properties remains unclear. Numerical simulations are carried out in order to answer this question. It is found that work hardening predominates in improving the yield strength and the ultimate tensile strength of the surface nano-crystallized graded materials, while the influence of the residual stress mainly emerges at the initial stage of deformation and decreases the apparent elastic modulus of the surface nano-crystallized graded materials, which agrees well with the experimental results.
\end{abstract}

(c) 2010 Elsevier B.V. All rights reserved.

\section{Introduction}

In recent years, surface nanocrystallization (SNC) technology attracts many researchers' interests since it can improve significantly many behaviors of metallic materials without changing the chemical compositions, such as the features of fatigue fracture, fretting fatigue, wear and corrosion [1]. Surface severe plastic deformation $\left(\mathrm{S}^{2} \mathrm{PD}\right)$, as a representative technique, can fabricate effectively surface nano-crystallized graded materials, which consist of a graded layer (GL) with grain size varying from tens of nanometers to a few micrometers and a coarse grained (CG) substrate with grain size in tens of micrometers, such as copper [2], Al-alloy [3], Fe [4] and stainless steel [5,6]. Due to different fabricating methods [7], $S^{2}$ PD includes shot peening (SP) [8-10], air blast shot peening (ABSP) [11-13], sandblasting (SB) [14-16], surface nanocrystallization and hardening $(\mathrm{SNH})$ [17-20], surface mechanical attrition treatment (SMAT) [1,5,21], particle impact processing (PIP) [11], etc. The fundamental procedure of $S^{2} \mathrm{PD}$ is to impact repeatedly the surface of CG materials with balls.

Many experiments have been done to investigate the improved mechanical properties of CG samples handled by $\mathrm{S}^{2} \mathrm{PD}$ technologies. For example, the $0.2 \%$ offset yield strength of a nickel-based alloy can increase $65 \%$ and $84 \%$ after 30 and $180 \mathrm{~min}$ SNH processing over CG samples, respectively, without losing obviously the ductil-

\footnotetext{
* Corresponding author. Tel.: +86 10 82543960; fax: +86 1082543977 E-mail address: chenshaohua72@hotmail.com (S. Chen).
}

ity [22]. The fatigue strength of a nickel-based Hastelloy C-2000 rises about $50 \%$ after $\mathrm{SNH}$ for $30 \mathrm{~min}$ [18]. Wear and friction properties of a low-carbon steel sheet can also be improved significantly after SMAT [1].

The improved properties are generally attributed to the refined structure, work-hardened region and residual stress in surface nano-crystallized graded materials, which should be induced by $S^{2} \mathrm{PD}$ process $[1,18,23]$. What is the individual contribution of these factors motivated further experimental and numerical studies. The experiments conducted by Lu et al. [9] show that the increased hardness and strength result from the gradient variation of grain size in the refined structure, rather than the residual stresses. However, Tian et al. [22] suggest that residual stress should play an important role in increasing the tensile strength using numerical simulations. Dai et al. [24] claimed that residual stress provides less contribution to the enhanced fatigue limit of the SNH-processed nickel alloy than surface work hardening. By means of heat-treating to partially remove the residual stress without strongly modifying the mechanical properties of the material, Panente and Guagliano [9] reveals that the improved fatigue crack propagation behavior is related more significant to surface work hardening than the residual stress field. However, the experiment which removes the residual stress by annealing cannot ensure an unchanged microstructure and the residual stress field is generated independently in an elastic-perfectly plastic model during numerical simulations. Thus, the individual effect of residual stress and work hardening on the improved mechanical properties of surface nano-crystallized graded materials remains still unclear. 


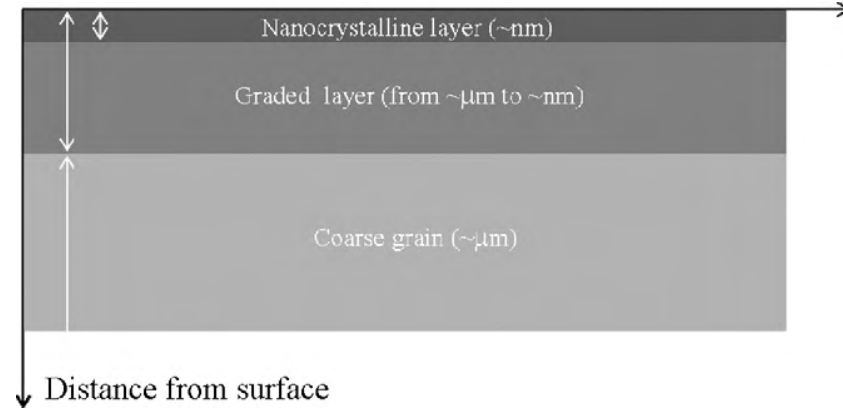

Fig. 1. Schematic of surface nano-crystallized graded materials, which include graded layer (GL) and coarse grain (CG) substrate. In the graded layer, if the grain size is less than $100 \mathrm{~nm}$, it is called nanocrystalline (NC) layer.

In this paper, the individual effect of residual stress (RS) and work hardening $(\mathrm{WH})$ is focused with numerical simulations. Two kinds of surface nano-crystallized graded materials are investigated, one is a soft material with low yield strain and the other is a stiff material with a relatively high yield strain. The results for both materials indicate that work hardening plays a dominating role in improving the tensile yield strength and ultimate tensile strength, while the effect of residual stress is mainly to decrease the apparent Young's modulus, which is consistent with the experimental results.

\section{Numerical simulation model}

Fig. 1 shows the schematic of a surface nano-crystallized graded material, in which there are a graded layer (GL) with grain size from tens of nanometers to a few micrometers, and a CG substrate with grain size in tens of micrometers. When the grain size is less than $100 \mathrm{~nm}$ in GL, the layers are called nano-crystallized (NC) layer. According to symmetric structure and the scale of the experimental sample, a surface nano-crystallized graded material under uniaxial tension, only $1 / 4$ structure is considered with the dimension of $4 \mathrm{~mm} \times 0.5 \mathrm{~mm}$ as shown in Fig. 2, in which the graded layer is $0.1 \mathrm{~mm}$ in thickness and CG substrate is $0.4 \mathrm{~mm}$ in thickness, the length of the FEM model is $4 \mathrm{~mm}$. The two symmetric planes lie at $x=0$ and $y=0$, respectively, as shown in Fig. 2 . This model comprises 148,500 4-node elements and 27 layers in GL. Each layer has different grain size, which leads to different mechanical properties. 2D PLANE55 and PLANE42 elements in the commercial finite element package ANSYS are used for the later thermal and structural analysis, respectively, in which PLANE42 can ensure the solution convergence for large tensile deformation.
In this study, in order to disclose the main factors that influence the yield strength and the ultimate tensile one of the surface nanocrystallized graded materials more clearly, we divide the materials into two classes according to the yield strain. The material with a small yield strain value is called a soft one and that has a relatively high yield strain is addressed as a stiff one. The yield strain is defined as the value of $E / \sigma_{0.2}$. In our former experiment, IF steel with different SMAT time belongs to a soft graded material, whose Young's modulus and Poisson's ratio are $200 \mathrm{GPa}$ and 0.28 , respectively. The constitutive relation of CG IF steel is expressed as

$\sigma_{\text {true }}=\left\{\begin{array}{ll}200000 \varepsilon_{\text {true }}, & \text { in elastic } \\ 501 \varepsilon_{\text {true }}^{0.29}, & \text { in plastic }\end{array}(\mathrm{MPa})\right.$

The constitutive relation of each layer in GL is assumed to have a similar expression:

$\sigma_{\text {true }}=\left\{\begin{array}{ll}200000 \varepsilon_{\text {true }}, & \text { in elastic } \\ k \varepsilon_{\text {true }}^{n}, & \text { in plastic }\end{array}(\mathrm{MPa})\right.$

where $k$ is a constant and $n$ the strain hardening exponent dependent on the grain size in each layer. Table 1 gives the parameters used in the numerical simulations, from which one can see that the value of $E / \sigma_{0.2}$ taken in this paper for a soft graded material is ten times of that for a stiff one.

According to our former experiment, the grain size in CG substrate is taken as $50 \mu \mathrm{m}$ and the smallest grain size in GL is $50 \mathrm{~nm}$. The maximum yield strength $(0.2 \%$ offset) and the smallest strain hardening exponent of the surface layer are set as $500 \mathrm{MPa}$ and 0.1 , respectively. From the experimental results [1-3], the grain size in GL is assumed to vary with the distance $h$ from surface as

$d=d_{0}+K_{d} h^{4}$

where $d_{0}=50 \mathrm{~nm}, K_{d}=4.955 \times 10^{6}$. Then, the thickness of NC layer is $19.5 \mu \mathrm{m}$.

Although the grain size is as small as $20 \mathrm{~nm}$ in GL, experiments $[6,25,26]$ find that the yield strength still follows the Hall-Petch relationship $[27,28]$. Therefore, Hall-Petch relation is adopted to describe the yield strength of each layer in GL:

$\sigma_{0.2}=\sigma_{0}+\frac{K_{y}}{\sqrt{d}}$

where $\sigma_{0}=74.0296 \mathrm{MPa}$ and $K_{y}=3.0121 \times 10^{3} \mathrm{MPa} \mathrm{nm}^{1 / 2}$. The $0.2 \%$ offset yield strength $\sigma_{0.2}$ is used here due to no evident yield point in the tensile stress-strain curve of IF steel.

According to the experimental observations by Jia et al. [29], the strain hardening exponent of ultrafine grained materials is seriously dependent on the grain size, when the grain size is less than
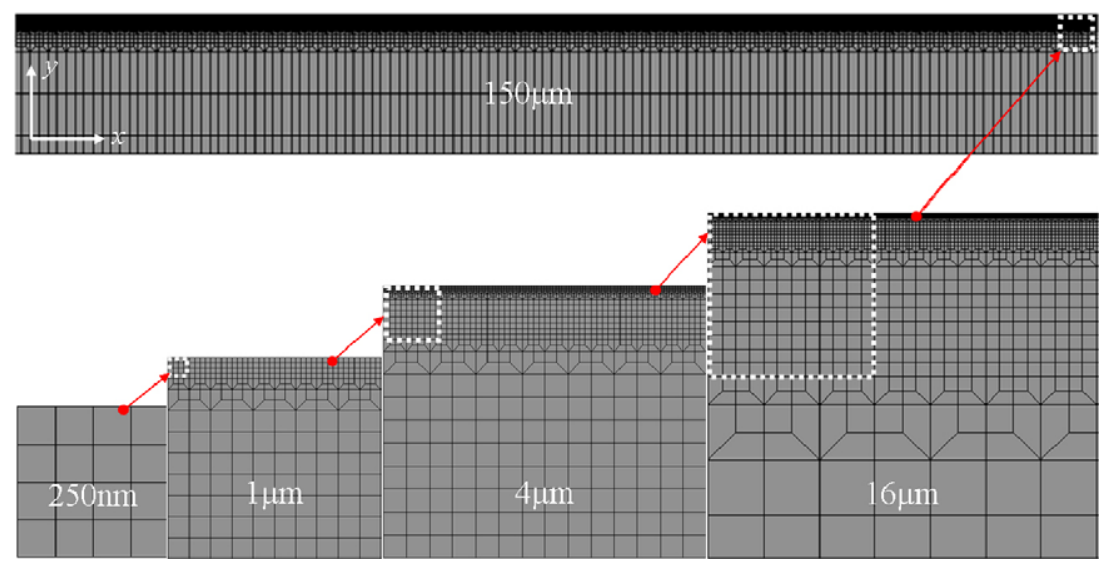

Fig. 2. Plot of the finite element model and the divided meshes. 
Table 1

The range and values of material parameters used in the present paper for the soft and stiff surface nano-crystallized graded materials.

\begin{tabular}{|c|c|c|c|c|c|}
\hline Material parameters & $E / \sigma_{0.2}$ & $E / G P a$ & $\sigma_{0.2} / \mathrm{MPa}$ & Grain size & $n$ \\
\hline Soft & $2285.71-400$ & 200 & $87.5-500$ & $50 \mathrm{~nm}-50 \mu \mathrm{m}$ & $0.29-0.1$ \\
\hline Hard & $200-40$ & 20 & $100-500$ & $50 \mathrm{~nm}-50 \mu \mathrm{m}$ & $0.29-0.1$ \\
\hline
\end{tabular}

$1 \mu \mathrm{m}$. Therefore, we assume the strain hardening exponents in GL has a similar varying trend as that of the yield strength in GL.

In order to demonstrate the individual effect of RS and $\mathrm{WH}$ on the tensile properties of surface nano-crystallized graded materials, numerical models with and without RS and WH will be first established. As in [24], RS and WH are produced by thermomechanical simulation approach, which has the same effect as the real process of $\mathrm{S}^{2} \mathrm{PD}$ but is more economical in computation and easier to control the range of residual stress and work hardening. Then the respective data of $\mathrm{RS}$ and $\mathrm{WH}$ in graded models can be separated according to [30].

\section{Results and discussions}

\subsection{The case of a soft surface nano-crystallized graded material}

Four cases with different residual stress and work hardening are generated by the thermomechanical technique to simulate samples produced by different $S^{2} P D$ time as shown in Fig. 3, in which the maximum compressive residual stresses are 676.16, 849.15, 955.04 and $1034.04 \mathrm{MPa}$, respectively. The distribution trends and values of the residual stresses are very similar to that in [22], where the maximum compressive residual stress is about $1200 \mathrm{MPa}$.

Fig. 4 shows the relation between the engineering stress and the engineering strain for the above four cases as well as the cases of CG sample and the surface nano-crystallized graded sample without RS and WH. From Fig. 4, one can see that the $0.2 \%$ offset yield strength of the graded sample without RS and WH increases by $50.34 \%$ over the CG sample, which indicates that grain refinement contributes significantly to the improvement of yield strength of the graded sample. Comparing the cases with RS and WH to the graded sample without RS and $\mathrm{WH}$, we find that the $0.2 \%$ offset yield strength is further increased by $14.33 \%, 31.79 \%, 42.06 \%$ and $46.26 \%$ over that of the later. These results show that residual stress and work hardening could render the graded sample's yield strength enhanced significantly, which is consistent with the experimental results in $[1,22]$ and our experimental results in Fig. 5.

Fig. 6 shows the detailed distributions of yield strength in each layer of the surface nano-crystallized graded samples with RS and $\mathrm{WH}$ as well as that of the CG sample. It is found that the yield strength is improved considerably due to $\mathrm{WH}$, even the yield

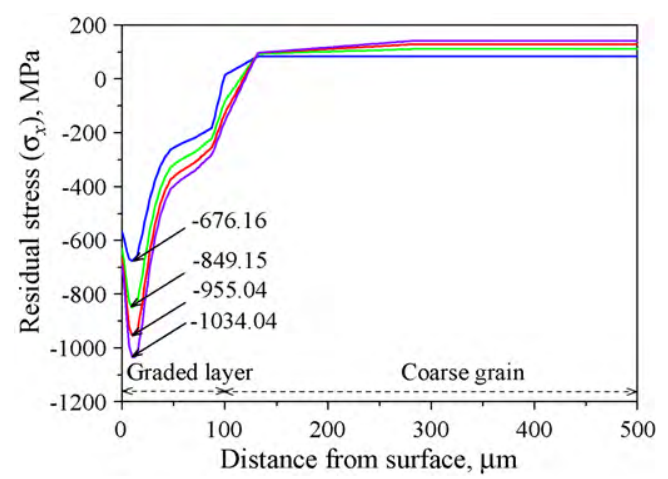

Fig. 3. The residual stress distribution from the surface to the center of the surface nano-crystallized graded material, which is produced by thermomechanical simulation.

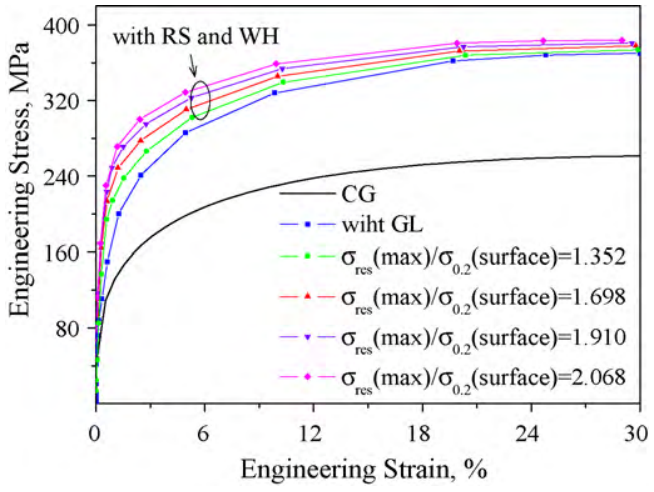

Fig. 4. The relation between the engineering stress and engineering strain for surface nano-crystallized graded materials under uniaxial tension, in which four kinds of states with different residual stress are considered as well as the graded sample without residual stress. That for the coarse grain sample is also included for comparison.

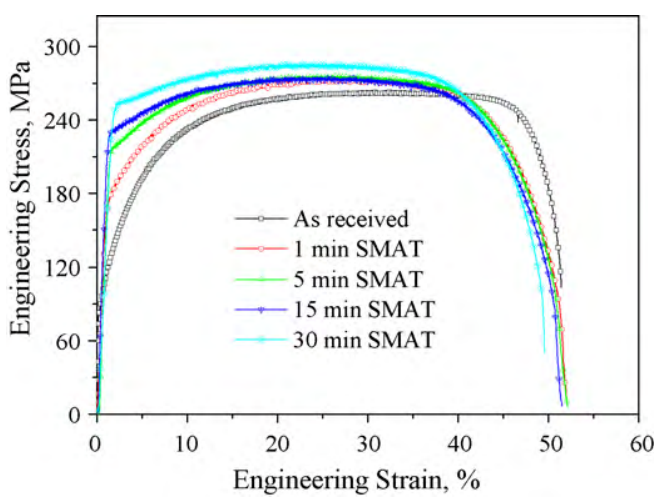

Fig. 5. Uniaxial tension experimental results of the engineering stress and engineering strain for surface nano-crystallized graded materials produced by different SMAT time. That for the coarse grain sample is also shown for comparison.

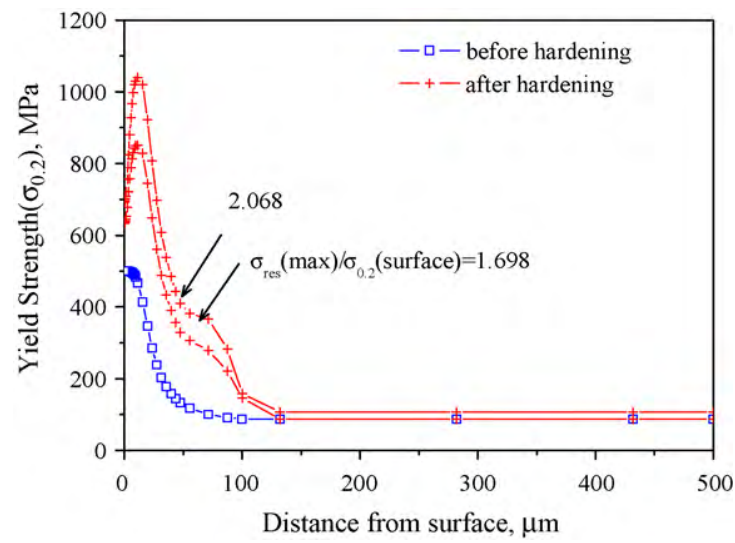

Fig. 6. Distributions of the yield stress via the distance from the surface to the center of the surface nano-crystallized graded material before and after work hardening. 


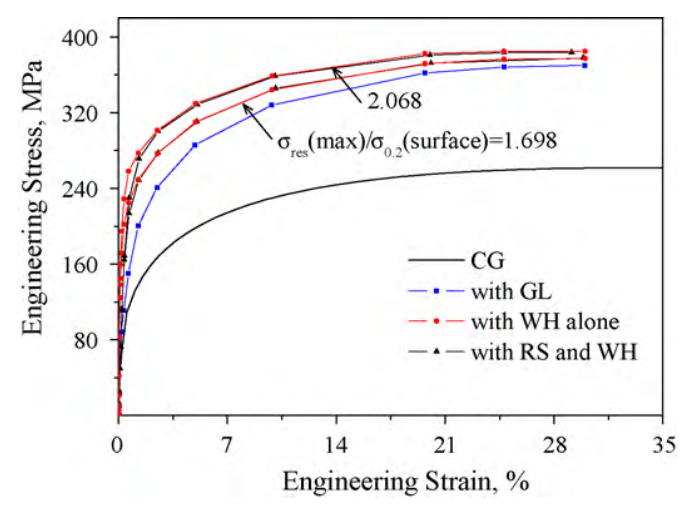

Fig. 7. The relation between the engineering stress and engineering strain obtained by numerical simulations for soft surface nano-crystallized graded samples with residual stress and work hardening or with work hardening alone. The corresponding relation for the graded material without residual stress and work hardening and that for the corresponding coarse grain material are also shown for comparison.

strength of the CG substrate increases slightly in the graded sample with $\sigma_{\text {res }}(\max ) / \sigma_{0.2}($ surface $)=2.068$.

The tensile engineering stress-strain curves for graded samples with WH only and that with both WH and RS are shown in Fig. 7 as well as that for CG sample and graded sample without WH and RS. It is found that the residual stress has no obvious influence on the tensile stress-strain curves in contrast to the case with WH only. Amplification of the tensile stress-strain curves at the initial deformation stage is shown in Fig. 8, where one can see that the residual stress only produces limited influence on the stress-strain relation in a shallow deformation range. The influenced deformation ranges are $(0,1.25 \%)$ and $(0,2.0 \%)$ for the cases with $\sigma_{\text {res }}(\max ) / \sigma_{0.2}($ surface $)=1.698$ and 2.068 , respectively.

Fig. 9 gives the amplified plot of stress-strain curves at the elastic deformation stage, which shows a decreasing elastic modulus due to RS. For the two specialized samples with $\sigma_{\text {res }}(\max ) / \sigma_{0.2}$ (surface $)=1.698$ and 2.068 , the apparent Young's modulus decreases from $200 \mathrm{GPa}$ to about $59 \mathrm{GPa}$ and $64 \mathrm{GPa}$ and the reduced amplitudes reach up about $70 \%$ and $68 \%$, respectively. It is consistent qualitatively with our experimental results for IF steel subjected to four different SMAT time with reduced amplitudes 89-91\%, as shown in Fig. 10.

From above, we conclude that the improved ultimate tensile strength and the yield one should be attributed to work hardening during $\mathrm{S}^{2} \mathrm{PD}$, while the residual stress decreases the apparent Young's modulus and shows influence on stress-strain curve at the stage of initially small deformation.

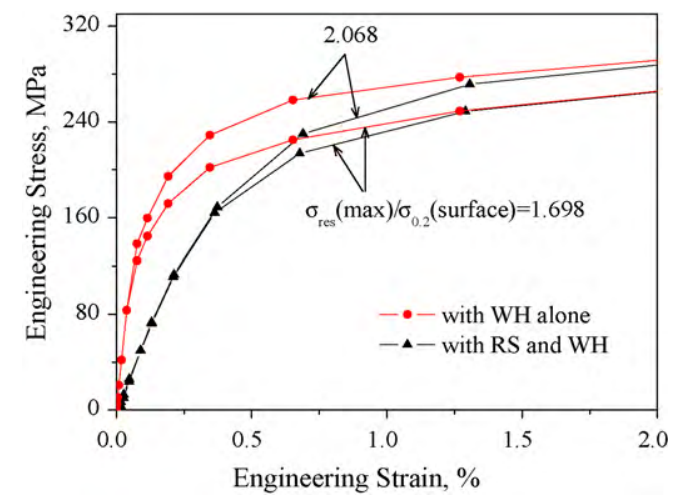

Fig. 8. Amplification of the initial stage of deformation in Fig. 7.

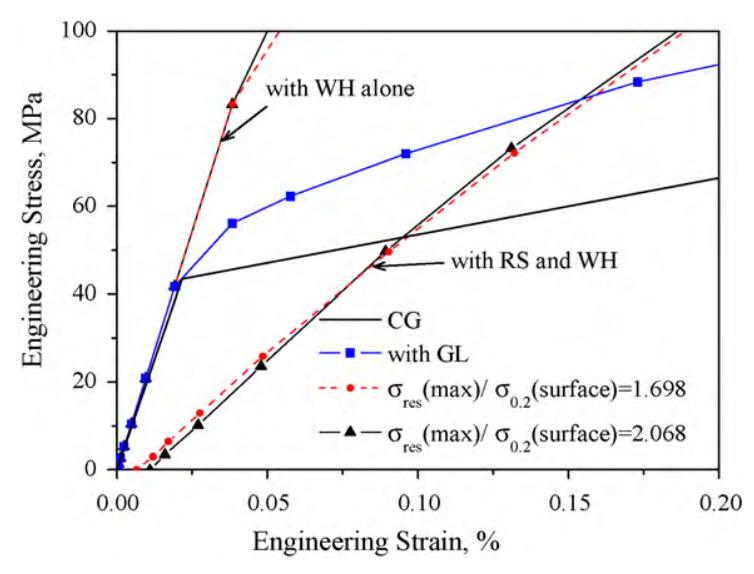

Fig. 9. Partial enlargement for the elastic deformation stage in Fig. 7.

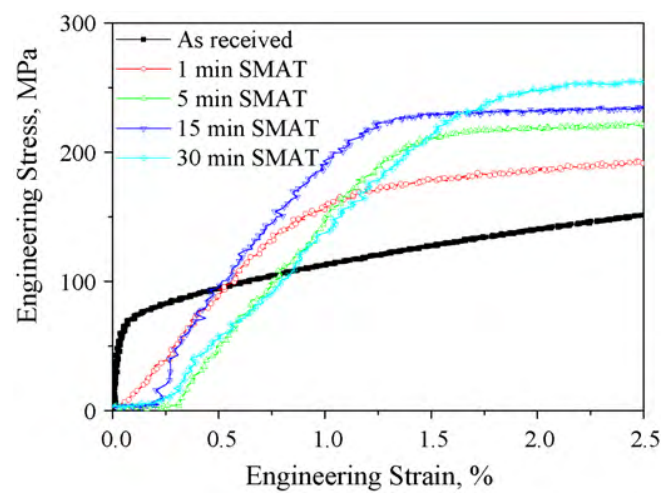

Fig. 10. Amplification of the experimental results in Fig. 5.

\subsection{The case of a stiff surface nano-crystallized graded material}

In this sub-section, a stiff surface nano-crystallized graded sample is investigated with the material parameters listed in Table 1. The ratio of the maximum residual stress to the $0.2 \%$ offset yield stress is $\sigma_{\text {res }}(\max ) / \sigma_{0.2}$ (surface) $=1.754$. Fig. 11 shows the tensile engineering stress-strain curves with and without residual stress or work hardening, as well as that for CG sample, using a similar method mentioned in Section 3.1. From Fig. 11, one can see that the influenced strain range by residual stress in stiff samples is much larger than that for soft samples, which reaches up to $(0$,

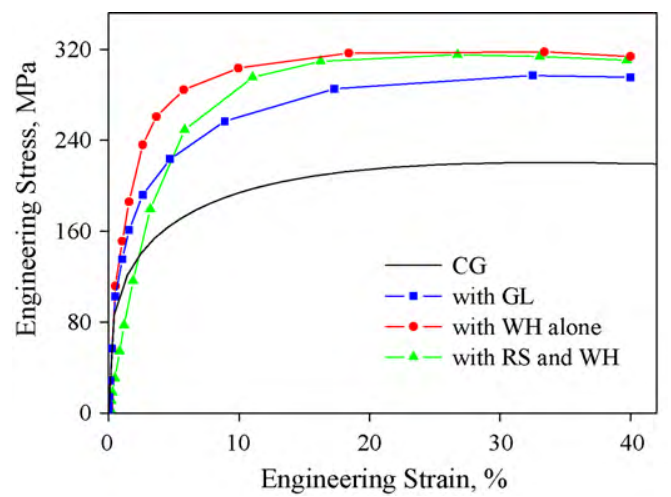

Fig. 11. The relation between the engineering stress and engineering strain obtained by numerical simulations for stiff surface nano-crystallized graded samples with residual stress and work hardening or with work hardening alone. The corresponding relation for the graded material without residual stress and work hardening and that for the corresponding coarse grain material are also shown for comparison. 


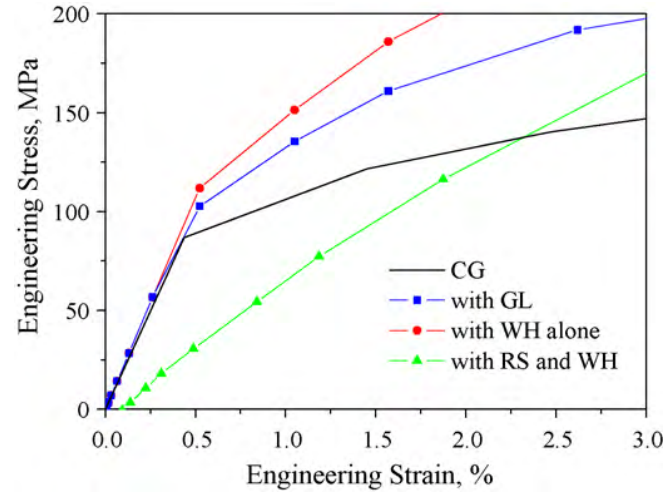

Fig. 12. Amplification for the elastic deformation stage in Fig. 11.

$20 \%)$, nearly ten times of that for the latter. The apparent Young's modulus reduces from 20 to $7.12 \mathrm{GPa}$ due to residual stress. The reduced amplitude is about $64.4 \%$ as shown in Fig. 12 . Comparing the case with WH alone and that with both WH and RS shows that the yield stress and the ultimate tensile strength are improved due to work hardening of the sample, which is consistent with that for a soft sample.

\section{Conclusions}

In this study, numerical simulation is used to investigate the individual contribution of residual stresses (RS) and work hardening $(\mathrm{WH})$ to the improved tensile properties of surface nanocrystallized graded materials, which is fabricated through $\mathrm{S}^{2} \mathrm{PD}$ on coarse grain materials. It is found that the initial stage of deformation in the tensile stress-strain curve of graded materials is sensitive to RS, and the influenced range of deformation increases along with the yield strain of the graded materials. The following part of stress-strain curve is hardly affected by RS, so that it can be inferred that RS does not show much influence on the ultimate tensile strength of graded materials. Comparing the case with work hardening alone and that with both work hardening and residual stress demonstrates that the improved ultimate tensile strength and the yield strength are owing to the effect of work hardening, while residual stress will reduce the apparent elastic modulus of surface nano-crystallized graded materials.

The finding in this paper should be helpful for further understanding the mechanism of the improved mechanical properties for surface nano-crystallized graded materials produced by $S^{2} \mathrm{PD}$ and can give some insights into the design of nano-crystallized materials.

Further study will be focused on the effect of microstructure evolutions as well as precisely experimental observations and measurements, which are not considered in the present work.

\section{Acknowledgements}

The work reported here is supported by NSFC through Grants \#10972220, \#10732050, and \#10721202, the key project of CAS through Grant KJCX2-YW-M04. The work of AS and JL is partially support by PolyU7/CRF/08 of Hong Kong.

\section{References}

[1] K. Lu, J. Lu, Mater. Sci. Eng. A 375 (2004) 38-45.

[2] Y.M. Wang, K. Wang, D. Pan, K. Lu, K.J. Hemker, E. Ma, Scripta Mater. 48 (2003) 1581-1586.

[3] X. Wu, N. Tao, Y. Hong, B. Xu, J. Lu, K. Lu, Acta Mater. 50 (2002) 2075-2084

[4] N.R. Tao, Z.B. Wang, W.P. Tong, M.L. Sui, J. Lu, K. Lu, Acta Mater. 50 (2002) 4603-4616.

[5] H.W. Zhang, Z.K. Hei, G. Liu, J. Lu, K. Lu, Acta Mater. 51 (2003) 1871-1881.

[6] T. Roland, D. Retraint, K. Lu, J. Lu, Scripta Mater. 54 (2006) 1949-1954.

[7] K. Dai, L. Shaw, Mater. Sci. Eng. A 430 (2006) 221-229.

[8] M. Guagliano, J. Mater. Process. Technol. 110 (2001) 277-286.

[9] I.F. Panente, M. Guagliano, Surf. Coat. Technol. 202 (2008) 3072-3080.

[10] Y. Todaka, M. Umemoto, J. Li, K. Tsuchiya, Rev. Adv. Mater. Sci. 10 (2005) 409-416.

[11] Y. Todaka, M. Umemoto, Y. Watanabe, K. Tsuchiya, in: S.G. Kang, T. Kobayashi (Eds.), Designing, Processing and Properties of Advanced Engineering Materials, Pts 1 and 2, 2004, pp. 1149-1152.

[12] Y. Todaka, M. Umemoto, K. Tsuchiya, Mater. Trans. 45 (2004) 376-379.

[13] M. Umemoto, Y. Todaka, K. Tsuchiya, Mater. Trans. 44 (2003) 1488-1493.

[14] X.Y. Wang, D.Y. Li, Electrochim. Acta 47 (2002) 3939-3947.

[15] D.Y. Li, L. Wang, W. Li, Mater. Sci. Eng. A 384 (2004) 355-360.

[16] D.Y. Li, Phys. Stat. Sol. a: Appl. Res. 191 (2002) 427-434.

[17] J.W. Tian, L. Shaw, P.K. Liaw, K. Dai, Mater. Sci. Eng. A 498 (2008) 216-224.

[18] J.C. Villegas, L.L. Shaw, K. Dai, W. Yuan, J. Tian, P.K. Liaw, D.L. Klarstrom, Philos. Mag. Lett. 85 (2005) 427-437.

[19] J.C. Villegas, K. Dai, L.L. Shaw, P.K. Liaw, Mater. Sci. Eng. A 410 (2005) 257-260.

[20] J.W. Tian, J.C. Villegas, W. Yuan, D. Fielden, L. Shaw, P.K. Liaw, D.L. Klarstrom, Mater. Sci. Eng. A 468 (2007) 164-170.

[21] Z.B. Wang, J. Lu, K. Lu, Acta Mater. 53 (2005) 2081-2089.

[22] J.W. Tian, K. Dai, J.C. Villegas, L. Shaw, P.K. Liaw, D.L. Klarstrom, A.L. Ortiz, Mater Sci. Eng. A 493 (2008) 176-183.

[23] S. Bagheri, M. Guagliano, Surf. Eng. 25 (2009) 3-14.

[24] K. Dai, L. Shaw, Int. J. Fatigue 30 (2008) 1398-1408.

[25] X.H. Chen, J. Lu, L. Lu, K. Lu, Scripta Mater. 52 (2005) 1039-1044.

[26] T. Roland, D. Retraint, K. Lu, J. Lu, Mater. Sci. Eng. A 445 (2007) 281-288.

[27] E.O. Hall, Proc. Phys. Soc. Lond. B 64 (1951) 742-747.

[28] N.J. Petch, J. Iron Steel Inst. 174 (1953) 25-28.

[29] D. Jia, K.T. Ramesh, E. Ma, Acta Mater. 51 (2003) 3495-3509.

[30] R.C. Juvinall, Engineering Considerations of Stress, Strain, and Strength, McGraw-Hill, New York, 1967. 